\title{
Genetic stability analysis and molecular depiction in elite entries of rice (Oryza sativa $\mathrm{L}$.)
}

\author{
Magdy Ahmad Al-kordy ${ }^{*}$, Hayam Fouad Ibrahim, Almoataz Bellah Ali El-Mouhamady and \\ Hamdy Mahmoud Abdel-Rahman
}

\begin{abstract}
Background: Genetic stability is considered one of the most important genetic tests used to ascertain the extent of genetic stability reached in plants; consequently, the goal of this research is to detect the degree of genetic stability of a group of a superior rice lines under different climatic environments.

Results: The seven entries of rice exhibited highly genetic stability depending on the results obtained from genetic stability analysis where they were recorded as high yielding; in addition, positive data for the remaining traits studied under the 12 environmental conditions were tested. Line numbers 1, 3, 4, and 5 were in the first rank for high genetic stability and high stable yielding under all experiments, while line numbers 2, 6, and 7 were recorded in the second rank. The values of broad sense heritability were very high in some traits (plant height, heading date, number of filled grains/panicle, grain yield/plant, and flag leaf area) which indicated that the genetic variance played an important role for controlling and inheriting these traits. A total of 101 fragments were generated using six primers of ISSR through comparison among the seven rice lines, where 34 of them were monomorphic and 67 bands were polymorphic with $66.33 \%$ polymorphism.

Conclusion: From the previous results, it could be concluded that the seven promising lines showed high genetic stability and recorded highly stable yielding under various environments which confirmed their importance in rice breeding programs for enhancing salinity tolerance, resistance to many diseases, and other stresses under Egyptian conditions.
\end{abstract}

Keywords: Rice, stable yield, stability analysis, broad sense heritability, genotypic variation, phenotypic variation, molecular markers, ISSR analysis

\section{Background}

The rice crop is considered one of the most important strategic food crops at local and global levels because it provides food to the vast majority of the world's population; it is also an important food for animals and birds through the production of fodder produced by rice straw pressing. Egypt grows about 770,000 acres of rice with an average productivity of 4.5 tons per acre; its production and cultivation areas are concentrated in the coastal governorates. Egypt is

\footnotetext{
*Correspondence: m_alkordy@yahoo.com

Genetics and Cytology Department, Genetic Engineering and Biotechnology Division, National Research Centre, 33 El Buhouth Street, Dokki, Giza 12622, Egypt
}

one of the African countries suffering from water poverty, especially after the construction of the Ethiopian renaissance dam. Therefore, the development of new tolerant rice lines for water-deficient and salinity conditions have become inevitable research trends. This will only be achieved if these genotypes prove to be highly correlated and have very high genetic stability in different regions and environmental conditions and this is what we will discuss in detail in the present investigation.

The following is a review of the most important research and studies that discussed the genetic stability and environmental undergrowth for various environmental conditions. Genetic value and stability were 
revealed in rice entries using selection indicators; the final results confirmed that index selection is considered one of the most important parameters for the development and increase of grain yield in rice plants in 49 rice lines in Iran (Fotokian and Agahi 2014). The impact of water stress on six promising lines of rice and their F1 crosses were performed by Eldessouky et al. (2016) who tested these materials under wet and drought conditions as well as comparing them using seven various primers from ISSR and showed that the seven primers used in this investigation generated 52 fragments, 37 of which were polymorphic with polymorphism $(71.15 \%)$, while the rest of bands were monomorphic. Heiba et al. (2016) exhibited the effect of some levels of heavy metals on yield and its trait components in rice genotypes using RAPD-PCR markers to compare the rice entries under study and the results exhibited that the entry genotypes (Sakha 106, GZ842312-9-4-5-1,IR 75, Giza 179 X IR 60, and GZ842312-9-4-5-1X IR 75) were recorded as highly tolerant for increasing the rates of heavy metals in soil as well the position of multi-environment treatises and its effect used for enhancing the resumption of rice yield toward diversified ambiences. Meanwhile, the rendering of rice genotypes in phlegmatic conditions was reported by Nanculao et al. (2016), estimating six rice entries beside four empirical genotypes within three regions over three years. They confirmed that the entry Quila 241319 is considered the preferable empirical genotype and was recorded as high yielding (11.3 t ha-1) as well as detecting high production stability using the environments; mercantile varieties were identified as moderate grain yield entries. On the same track, Onyia et al. (2017) lectured genetic variability and rapport of some agronomic characters of rice and their assists for yield by using 12 rice entries for expansion and yield manifestation in south-eastern Nigeria and detected that the entries (WAB 33-25, WAB 56-1-FX2, WAB 56-39, WAB 56-125, ITA 150, and FAROX $16(\mathrm{LC})$ ) recorded the highest stable production genotypes within two seasons of the trial. While genetic stability and heritability in the broad sense were found in seven soybean genotypes in three regions, two sowing dates and two seasons were estimated by El-Mouhamady et al. (2017) who confirmed that the entries (Crawford, Giza 21, Giza 22, Giza 35, Giza 83, and Giza 111) were recorded as highly genetically stable according to the data of stability analysis under all conditions. The genetic stability that was discussed included certain traits, especially grain yield/ plant in some promising rice entries under control and water-deficit conditions pending venereal interval and the final results confirmed that the entries
(IR83142-B-7-B-B, Binuhangin, IR77298-14-1-2-13, IR70215-70-CPA-3-4-1-3, and IR77298-14-1-2) recorded high genetic stability and were better stable for the final production of yielding under the two conditions over 11 years, respectively (Torres and Henry 2018). The main objective of this study is to ascertain the degree of genetic stability and environmental acclimatization for the seven rice entries being studied. In the past, these lines have shown a high tolerance to salinity and a high level of heavy metals in various regions beside different kinds of diseases and the test of water stress resistance will come in future years.

\section{Materials and Methods \\ Plant material}

Seven rice entries were planted in three regions under two different dates of sowing during the 2016 and 2017 seasons in a randomized complete block design with three replicates for each experiment. The three locations were: The Farm of Taj El-Ezz, Mansoura city, Dakahlia Governorate; The Farm of Sakha City, Kafrel-Skeikh Governorate; and Al-Adliya Village, Belbeis Center, Sharkia Governorate, Egypt. All experiments were conducted through two planting dates during the 2016 and 2017 seasons: 1 May and 10 May.

It should be noted that these entries were obtained by hybridization between their different parents subscribers to its production using half diallel analysis without reciprocals to get the first generation hybrid in the season (2009) and then continued to cultivate these crosses and self- propagation beside the simple selection after each selecting generation from the second generation (or the first selecting generation) until the season (2015, i.e.,) access to the seventh generation (F7) in which all the hybrids proved highly genetic stability, great appearance and excellence for different traits; such as high yielding trait, tolerance for high level of salinity, highly limit of heavy metals and various diseases for example leaf blast, nick blast and stem borer to be called lines and then used in the current study. The previous seven rice entries mentioned above have proved remarkable superiority in the resistance for high limit salinity of soil, high levels of heavy metals and also resistant to a large number of diseases of rice, but not yet tested for water stress resistance and this point will be verified in the coming years and in many pilot sites, So that it can be said it is resistant to water deficit under Egyptian conditions.

\section{Studied traits}

The most important traits calculated under all conditions within the two seasons were plant height, heading 
date, 1000-grain weight, number of panicles/plant, number of filled grains/panicle, grain yield/plant, and flag leaf area, respectively. The aim of this investigation was to know the degree of the variety's constancy under all circumstances; this gives a good impression for the degree of genetic stability, localization, and adaptation under Egyptian conditions.

\section{Stability analysis design}

Stability analysis was carried out according to Eberhart and Russell (1966); in this analysis, two parameters were obtained, $b$ and $S^{2} d$ (regression coefficient and mean squares of deviation from regression, respectively) of the performance on environmental indices. Yield-stability statistic was calculated using the program STABLE (a basic program for calculating stability and yield-stability statistic) after Kang and Magari (1995). Both types of heritability were estimated for the former traits, as illustrated by Collins et al. (1987); the coefficient of variability values was estimated depending on phenotypic (P.C.V.) and genotypic (G.C.V.) variances according to Kehr and Gardner (1960) and Yassin (1973) (Table 1).

\section{Molecular markers ISSR profiles}

Total DNA extraction The extraction method was applied according to Zietkiewicz and Rafalski (1994) and the ISSR primers were procured from UBC (University of British Columbia, biotechnology laboratory, Vancouver, Canada) based on core repeats anchored at the 5 or 3 end as shown in Table 9. DNA of seven rice varieties was amplified using Taq-DNA polymerase chain reaction (PCR) according to the manufacturer's instructions (Promega \# TM048) for ISSR primers The PCR consisted of a 3-min incubation period at $94{ }^{\circ} \mathrm{C}$ followed by 35 cycles of $94{ }^{\circ} \mathrm{C} / 30 \mathrm{~s}\left(38,40,41\right.$, and $45^{\circ}$ C) $/ 1 \mathrm{~min}$ and $72{ }^{\circ} \mathrm{C} / 2 \mathrm{~min}$, with a final extension step of $72{ }^{\circ} \mathrm{C} / 7 \mathrm{~min}$. The PCR product was separated by $1.2 \%$ agarose gel electrophoresis using a TAE buffer.
Data handling and cluster analysis (phylogenetic tree) Data were scored for computer analysis based on the presence or absence of the amplified products for each of the six ISSR primers. Pairwise components of the seven rice lines based on the presence or absence of unique and shared polymorphic products were used to determine similarity coefficients. The similarity coefficients were then used to construct dendrograms, using the unweighted pair group method with arithmetic averages (UPGMA) employing the SAHN (Sequential, Agglomerative, Hierarchical and Nested clustering) from the NTSYS-PC (Numerical Taxonomy and Multivariate Analysis System), version 1.80 (Applied Biostatistics Program) according to Jaccard (1908).

\section{Results}

\section{Variation and interaction}

Highly significant variances were obtained between all lines studied confirming the effective role of a genetic variation for elucidating and concreting form among all these entries (Table 2). The data obtained from mean squares variations of the environments were highly significant, indicating that environmental factors contributed to and increased the fruitful role responsible for the recognized genotypic performance beside the results observed in the same table exhibited that highly significant variances were generated from the interactions among entries and environments for all traits calculated in the seven rice lines. The data clearing in Table 3 related with F-Ratio were found to be significant and highly significant variances for all characters calculated of the most parameters estimated especially; (S.O.V) components within the ANOVA test for stability analysis design (Table 3).

\section{Mean performance}

The entries with the highest mean performances for all studied traits under the 12 environments were L1, L3, L4, and L5 (Tables 4, 5, 6, 7, 8, 9 and 10). The respective values were: plant height $=89.36$, 101.10, 99.70, and $90.32 \mathrm{~cm}$ (Table 4); heading date

Table 1 Names of the seven rice entries

\begin{tabular}{|c|c|c|c|c|c|}
\hline No. & Names of lines & Reaction for salinity, high level of heavy metals and diseases & Origin & Types of elicitation & Duration \\
\hline 1 & LI: Agami X Sakha 101 & Resistance & Egypt & By hybridization & 122 \\
\hline 2 & L2: Agami X Giza 177 & Resistance & Egypt & By hybridization & 136 \\
\hline 3 & L3: GZ1368-S-5-4 X Giza 177 & Resistance & Egypt & By hybridization & 121 \\
\hline 4 & L4: Gaori X Sakha 101 & Resistance & Egypt & By hybridization & 135 \\
\hline 5 & L5: Gaori X Sakha 104 & Resistance & Egypt & By hybridization & 120 \\
\hline 6 & L6: Gaori X GZ1368-S-5-4 & Resistance & Egypt & By hybridization & 138 \\
\hline 7 & L7: Sakha 104 X Giza 182 & Resistance & Egypt & By hybridization & 140 \\
\hline
\end{tabular}


Table 2 Mean squares of all traits evaluated in rice entries during stability analysis

\begin{tabular}{|c|c|c|c|c|c|c|c|c|}
\hline \multirow[t]{2}{*}{ S.O.V } & \multirow[t]{2}{*}{ D.F } & \multicolumn{7}{|l|}{ M.S } \\
\hline & & $\begin{array}{l}\text { Plant } \\
\text { height }\end{array}$ & $\begin{array}{l}\text { Heading } \\
\text { date }\end{array}$ & $\begin{array}{l}\text { 1000-grain } \\
\text { weight }\end{array}$ & $\begin{array}{l}\text { Number of } \\
\text { panicles/plant }\end{array}$ & $\begin{array}{l}\text { Number of filled } \\
\text { grains/panicle }\end{array}$ & $\begin{array}{l}\text { Grain yield/ } \\
\text { plant }\end{array}$ & $\begin{array}{l}\text { Flag leaf } \\
\text { area }\end{array}$ \\
\hline Environments & 11 & $12.67^{\mathrm{a}}$ & $32.89^{\mathrm{a}}$ & $17.54^{\mathrm{a}}$ & $3.60^{\mathrm{a}}$ & $20.15^{a}$ & $4.60^{\mathrm{a}}$ & $9.37^{\mathrm{a}}$ \\
\hline Blocks in (E) & 2 & 0.84 & 1.37 & 2.36 & 2.45 & 1.71 & 2.39 & 1.78 \\
\hline Genotypes & 6 & $5.43^{\mathrm{a}}$ & $11.04^{\mathrm{a}}$ & $3.28^{\mathrm{a}}$ & $20.43^{\mathrm{a}}$ & $10.15^{\mathrm{a}}$ & $1.72^{\mathrm{a}}$ & $3.38^{\mathrm{a}}$ \\
\hline Genotypes $\times$ environments & 66 & $4.77^{\mathrm{a}}$ & $9.80^{\mathrm{a}}$ & $10.37^{\mathrm{a}}$ & $16.40^{\mathrm{a}}$ & $3.70^{\mathrm{a}}$ & $6.90^{\mathrm{a}}$ & $30.78^{a}$ \\
\hline Error & 144 & 0.88 & 0.74 & 0.53 & 1.79 & 2.05 & 1.26 & 1.12 \\
\hline $\begin{array}{l}\text { Environments }+ \text { (genotypes } \times \\
\text { environments) }\end{array}$ & 77 & $1.29^{\mathrm{a}}$ & $32.68^{\mathrm{a}}$ & $7.18^{\mathrm{a}}$ & $6.43^{\mathrm{a}}$ & $0.78^{\mathrm{a}}$ & $18.86^{\mathrm{a}}$ & $0.70^{\mathrm{a}}$ \\
\hline Environmental (linear) & 1 & $0.73^{a}$ & $15.70^{\mathrm{a}}$ & $15.58^{\mathrm{a}}$ & $10.92^{\mathrm{a}}$ & $1.30^{\mathrm{a}}$ & $1.42^{\mathrm{a}}$ & $28.39^{a}$ \\
\hline $\begin{array}{l}\text { (Genotypes } \times \text { environments) } \\
\text { Linear }\end{array}$ & 6 & $2.40^{\mathrm{a}}$ & $1.63^{\mathrm{a}}$ & $9.21^{\mathrm{a}}$ & $1.50^{\mathrm{a}}$ & $12.08^{\mathrm{a}}$ & $41.70^{\mathrm{a}}$ & $19.78^{\mathrm{a}}$ \\
\hline Pooled deviation & 7 & $11.46^{\mathrm{a}}$ & $17.03^{\mathrm{a}}$ & $14.31^{\mathrm{a}}$ & $4.27^{\mathrm{a}}$ & $4.29^{\mathrm{a}}$ & $0.53^{\mathrm{a}}$ & $14.06^{\mathrm{a}}$ \\
\hline Pooled error & 168 & 0.65 & 0.28 & 1.69 & 2.68 & 0.83 & 1.43 & 0.73 \\
\hline
\end{tabular}

a $P \leq 0.01$

$=91.67,91.21,104.39$, and 88.76 days (Table 5); 1000 -grain weight $=32.20,36.14,35.23$, and 35.45 gm (Table 6); number of panicles/plant $=33.04$, 37.01, 36.14, and 32.89 (Table 7); number of filled grains $/$ panicle $=191.77,207.55,203.66$, and 204.42 (Table 8); grain yield/plant $=79.04,80.55,74.33$, and $72.51 \mathrm{gm}$ (Table 9); and flat leaf area $=45.66,57.41$, 58.83 , and $58.0 \mathrm{~cm}$ (Table 10). In the same regard, the results observed in Table 11 revealed that the entry numbers $1,3,4$, and 5 exhibited the highest mean values for the seven studied traits under all environments tested which indicated that these lines were very genetically stable and were found to be highly conforming and timely under different conditions. On the same track, the rest line numbers 2, 6, and 7 also achieved good results for all studied traits and came in the second trend, respectively. Data cleared in Table 12, for example, showed the most desirable and important environments for the studied traits of all lines under study. These environments were: R1 FPD Y1, R1 SPD Y1, R1 FPD Y2, and R2 SPD Y2 for plant height trait; R1 SPD Y2, R2 FPD Y1, R3 FPD Y1, and R3 SPD Y2 for heading date trait; and R1 FPD Y2, R2 SPD Y2, R3 FPD Y1, and R3 SPD Y2 for grain yield/plant (gm), and so on. These environments exhibited high genetic stability, detected the better results, and were highly stable for all traits calculated in all studied materials.

\section{Stability parameters}

The data calculated and presented in Table 13 revealed that the best rates of the parameter of bi (regression coefficient) were obtained in the rice lines L1, L3, L4, and L5 for the seven traits being studied. These entries straightened to the one or neighing from it, which revealed the riskiness, highly genetic stability, and the range of their modification for various mediums and states, while the data were higher

Table 3 F-ratio values for the components of stability analysis

\begin{tabular}{|c|c|c|c|c|c|c|c|}
\hline S.O.V & $\begin{array}{l}\text { Plant } \\
\text { height }\end{array}$ & $\begin{array}{l}\text { Heading } \\
\text { date }\end{array}$ & $\begin{array}{l}\text { 1000-grain } \\
\text { weight }\end{array}$ & $\begin{array}{l}\text { Number of } \\
\text { panicles/plant }\end{array}$ & $\begin{array}{l}\text { Number of filled grains/ } \\
\text { panicle }\end{array}$ & $\begin{array}{l}\text { Grain yield/ } \\
\text { plant }\end{array}$ & $\begin{array}{l}\text { Flag leaf } \\
\text { area }\end{array}$ \\
\hline Environments & 14.39 & 44.44 & 33.09 & 2.01 & 9.82 & 3.65 & 8.36 \\
\hline Blocks in (E) & 0.95 & 1.85 & 4.45 & 1.36 & 0.83 & 1.89 & 1.58 \\
\hline Genotypes & 6.17 & 14.91 & 6.18 & 11.41 & 4.95 & 1.36 & 3.01 \\
\hline Genotypes $\times$ environments & 5.42 & 13.24 & 19.56 & 9.16 & 1.80 & 5.47 & 27.48 \\
\hline $\begin{array}{l}\text { Environments + (genotypes } \times \\
\text { environments) }\end{array}$ & 1.98 & 116.71 & 4.24 & 2.39 & 0.93 & 13.18 & 0.95 \\
\hline Environmental (linear) & 1.12 & 56.07 & 9.21 & 4.07 & 1.56 & 0.99 & 38.89 \\
\hline $\begin{array}{l}\text { (Genotypes } \times \text { environments) } \\
\text { Linear }\end{array}$ & 3.69 & 5.82 & 5.44 & 0.55 & 14.55 & 29.16 & 27.09 \\
\hline Pooled deviation & 17.63 & 60.82 & 8.46 & 1.59 & 5.16 & 0.73 & 19.26 \\
\hline
\end{tabular}

Probability $>F=<0.0001$ 
Table 4 The mean values for the seven rice entries under the 12 environments for plant height

\begin{tabular}{lllllllll}
\hline Environments & LI & L2 & L3 & $L 4$ & $L 5$ & $L 6$ & L7 & Mean \\
\hline R1 FPD Y1 & 89.50 & 105.0 & 98.0 & 100.0 & 88.60 & 107.40 & 99.18 & 98.24 \\
R1 SPD Y1 & 92.70 & 102.60 & 96.50 & 92.80 & 87.0 & 97.80 & 102.16 & 95.93 \\
R1 FPD Y2 & 90.12 & 103.0 & 100.0 & 96.0 & 92.77 & 95.89 & 100.70 & 96.92 \\
R1 SPD Y2 & 88.56 & 108.33 & 102.70 & 105.43 & 90.50 & 104.60 & 97.0 & 99.58 \\
R2 FPD Y1 & 85.34 & 110.65 & 104.20 & 102.0 & 89.20 & 99.69 & 104.67 & 99.39 \\
R2 SPD Y1 & 87.0 & 104.70 & 99.57 & 103.39 & 85.0 & 103.40 & 105.70 & 98.39 \\
R2 FPD Y2 & 90.84 & 102.80 & 105.87 & 100.89 & 95.03 & 100.27 & 102.60 & 99.75 \\
R2 SPD Y2 & 86.0 & 107.48 & 100.42 & 97.55 & 90.18 & 106.33 & 98.50 & 98.06 \\
R3 FPD Y1 & 90.55 & 112.0 & 98.67 & 102.0 & 93.0 & 101.85 & 107.54 & 100.80 \\
R3 SPD Y1 & 93.0 & 109.60 & 106.60 & 95.78 & 92.36 & 103.86 & 95.38 & 99.51 \\
R3 FPD Y2 & 87.30 & 106.0 & 103.28 & 106.89 & 86.0 & 102.69 & 100.58 & 98.96 \\
R3 SPD Y2 & 91.50 & 105.63 & 97.48 & 93.68 & 94.30 & 105.70 & 103.0 & 98.75 \\
Mean & $\mathbf{8 9 . 3 6}$ & 106.48 & $\mathbf{1 0 1 . 1 0}$ & $\mathbf{9 9 . 7 0}$ & $\mathbf{9 0 . 3 2}$ & 102.45 & 101.41
\end{tabular}

than or lower than the unity were obtained in the two tracks for the same traits in the entry numbers 2,6 , and 7 , respectively. With respect to the $S^{2} \mathrm{di}$ parameter, the data shown in Table 13 confirmed that the entry numbers $1,3,4$, and 5 recorded the value 0.0 or adjacent to it. For the data calculated for the parameter $R^{2}$ in the same table, it could be concluded that the entries L1, L3, L4, and L5 for the seven studied traits recorded the best results of steadiness and the data ambit in the range of 97.3299.11\% for plant height trait, $97.38-99.07 \%$ for heading date trait, $95.60-99.80 \%$ for 1000 -grain weight trait, $94.58-99.95 \%$ for number of panicles/plant trait, $91.15-99.85 \%$ for number of filled grains/panicle trait, $98.04-99.58 \%$ for grain yield/plant trait, and $89.99-99.64 \%$ for flag leaf area trait, respectively.
The results shown in Table 14 illustrated that the six environments (R1 SPD Y1, R1 SPD Y2, R2 SPD Y1, R2 FPD Y2, R3 SPD Y1, and R3 SPD Y2) were recording the best conditions for manufacturing highly genetic stability for the previous testing materials through estimating all studied traits; the three stability parameters confirmed these results where bi equalized or was close to $1, S^{2}$ di equalized or was close to 0 , whereas the high percentages of $\mathrm{R}^{2}$ were observed in the previous excellent environments where the values were close to $100 \%$.

\section{Genetic components}

The results in Table 15 revealed that the values of genotypic and phenotypic variation were higher than the values of pooled error or error variation for the

Table 5 The mean values for the seven rice entries under the 12 environments for heading date

\begin{tabular}{lllllllll}
\hline Environments & LI & L2 & $L 3$ & $L 4$ & $L 5$ & $L 6$ & L7 & Mean \\
\hline R1 FPD Y1 & 91.0 & 105.56 & 89.0 & 112.0 & 88.90 & 112.33 & 112.30 & 101.58 \\
R1 SPD Y1 & 88.0 & 107.88 & 91.76 & 106.0 & 87.76 & 110.64 & 110.23 & 100.32 \\
R1 FPD Y2 & 92.33 & 110.0 & 91.0 & 111.33 & 90.0 & 108.33 & 109.80 & 101.82 \\
R1 SPD Y2 & 90.50 & 102.78 & 90.33 & 108.34 & 86.43 & 108.89 & 110.23 & 99.64 \\
R2 FPD Y1 & 89.70 & 106.0 & 88.70 & 103.47 & 91.05 & 109.0 & 109.37 & 99.61 \\
R2 SPD Y1 & 93.0 & 104.22 & 92.0 & 101.44 & 87.0 & 110.18 & 113.0 & 100.12 \\
R2 FPD Y2 & 92.50 & 107.88 & 93.0 & 100.78 & 89.40 & 104.77 & 110.46 & 99.82 \\
R2 SPD Y2 & 90.88 & 109.66 & 91.50 & 99.58 & 90.06 & 107.50 & 114.0 & 100.45 \\
R3 FPD Y1 & 95.0 & 100.0 & 89.23 & 102.0 & 87.79 & 109.32 & 109.55 & 98.98 \\
R3 SPD Y1 & 93.45 & 105.87 & 94.0 & 103.0 & 91.70 & 105.80 & 108.72 & 100.36 \\
R3 FPD Y2 & 92.0 & 110.78 & 92.60 & 104.26 & 88.30 & 107.37 & 107.27 & 100.36 \\
R3 SPD Y2 & 91.73 & 102.64 & 91.45 & 100.53 & 86.78 & 103.87 & 105.28 & 97.46 \\
Mean & $\mathbf{9 1 . 6 7}$ & 106.10 & $\mathbf{9 1 . 2 1}$ & $\mathbf{1 0 4 . 3 9}$ & $\mathbf{8 8 . 7 6}$ & 108.16 & 110.01 & 100.04 \\
\hline
\end{tabular}


Table 6 The mean values for the seven rice entries under the 12 environments for 1000-grain weight

\begin{tabular}{lllllllll}
\hline Environments & L & $L 2$ & $L 3$ & $L 4$ & $L 5$ & $L 6$ & L7 \\
\hline R1 FPD Y1 & 31.50 & 25.88 & 35.60 & 37.12 & 39.0 & 24.36 & 28.34 & 31.68 \\
R1 SPD Y1 & 29.48 & 28.40 & 37.33 & 29.33 & 33.21 & 25.60 & 25.20 & 29.79 \\
R1 FPD Y2 & 30.18 & 27.49 & 36.45 & 34.57 & 32.60 & 30.19 & 30.44 & 31.70 \\
R1 SPD Y2 & 35.0 & 26.0 & 33.68 & 35.44 & 29.80 & 22.50 & 24.59 & 29.57 \\
R2 FPD Y1 & 33.78 & 25.33 & 38.0 & 38.55 & 35.33 & 23.40 & 27.55 & 31.70 \\
R2 SPD Y1 & 32.64 & 28.90 & 35.63 & 37.26 & 36.37 & 26.67 & 28.77 & 32.32 \\
R2 FPD Y2 & 29.60 & 27.0 & 34.20 & 36.44 & 38.26 & 32.58 & 27.43 & 32.21 \\
R2 SPD Y2 & 33.80 & 24.77 & 37.88 & 35.26 & 34.79 & 27.65 & 27.57 & 31.67 \\
R3 FPD Y1 & 34.78 & 26.50 & 36.22 & 34.68 & 36.55 & 21.19 & 24.78 & 30.67 \\
R3 SPD Y1 & 31.0 & 23.40 & 35.34 & 38.0 & 37.36 & 25.33 & 28.58 & 31.28 \\
R3 FPD Y2 & 30.66 & 25.45 & 37.82 & 32.77 & 33.84 & 24.39 & 23.87 & 29.82 \\
R3 SPD Y2 & 34.06 & 27.32 & 35.60 & 33.40 & 38.30 & 22.50 & 26.49 & 31.09 \\
Mean & $\mathbf{3 2 . 2 0}$ & 26.37 & $\mathbf{3 6 . 1 4}$ & $\mathbf{3 5 . 2 3}$ & $\mathbf{3 5 . 4 5}$ & $\mathbf{2 5 . 5 3}$ & 26.96
\end{tabular}

seven studied traits which confirmed that the number of replicates utilized in these experiments of these lines for the previous characters were appropriate to confer the best determination for the error variance. The values of heritability appeared to be low for the traits 1000-grain weight and number of panicles/plant: the results were $76.94 \%$ and $72.73 \%$; and were seen to be very high for the traits plant height, heading date, number of filled grains/panicle, grain yield/plant, and flag leaf area: the results were $88.96 \%, 94.09 \%, 80.96 \%, 82.43 \%$, and $80.53 \%$, respectively. Results observed in Table 15 showed that the values of G.C.V. and P.C.V. appeared to be depressed or low for the traits plant height, heading date, number of filled grains/panicle, grain yield/ plant, and flag leaf area, while the other traits (1000-grain weight and number of panicles/plant) recorded values shown to be moderate and close to $50 \%$. After all that has been presented in the previous parts, it must be pointed out that the seven promising rice lines which showed unparalleled superiority in the extent of genetic stability, high yield, and tolerance to many environmental stresses and diseases still did not give a definitive view of resistance to water stress and this will be determined in the future studies.

\section{Molecular description using ISSR primers ISSR analysis profile}

The six ISSR primers-17898-B, 17899-B, HB-12, 17898-A, 17899-A, and 844-B-produced a total of 101 markers, 34 of them were monomorphic, while 67

Table 7 The mean values for the seven rice entries under the 12 environments for number of panicles/plant

\begin{tabular}{|c|c|c|c|c|c|c|c|c|}
\hline Environments & $\mathrm{LI}$ & $\mathrm{L} 2$ & L3 & L4 & $\mathrm{L} 5$ & L6 & L7 & Mean \\
\hline R1 FPD Y1 & 34.56 & 28.67 & 37.0 & 34.65 & 31.07 & 24.99 & 29.55 & 31.49 \\
\hline R1 SPD Y1 & 29.80 & 29.0 & 38.55 & 35.88 & 29.55 & 27.32 & 30.0 & 31.44 \\
\hline R1 FPD Y2 & 30.0 & 30.36 & 35.40 & 32.64 & 33.20 & 25.38 & 26.18 & 30.45 \\
\hline R1 SPD Y2 & 27.66 & 28.68 & 39.0 & 37.70 & 31.60 & 28.46 & 25.04 & 31.16 \\
\hline R2 FPD Y1 & 31.66 & 27.98 & 35.69 & 35.77 & 32.58 & 23.77 & 27.13 & 30.65 \\
\hline R2 SPD Y1 & 33.34 & 30.33 & 33.84 & 38.43 & 30.77 & 22.63 & 25.15 & 30.64 \\
\hline R2 FPD Y2 & 35.04 & 31.48 & 38.53 & 39.37 & 32.74 & 28.55 & 26.0 & 33.10 \\
\hline R2 SPD Y2 & 29.78 & 30.27 & 37.78 & 36.32 & 31.27 & 29.32 & 24.11 & 31.26 \\
\hline R3 FPD Y1 & 34.76 & 26.55 & 36.90 & 34.90 & 26.33 & 27.33 & 28.02 & 30.68 \\
\hline R3 SPD Y1 & 36.80 & 29.57 & 38.97 & 35.88 & 39.42 & 28.20 & 27.77 & 33.80 \\
\hline R3 FPD Y2 & 35.50 & 31.29 & 34.79 & 34.77 & 38.94 & 26.25 & 26.27 & 32.54 \\
\hline R3 SPD Y2 & 37.60 & 28.69 & 37.70 & 37.41 & 37.30 & 21.33 & 23.78 & 31.97 \\
\hline Mean & 33.04 & 29.40 & 37.01 & 36.14 & 32.89 & 26.12 & 26.58 & 31.59 \\
\hline
\end{tabular}


Table 8 The mean values for the seven rice entries under all conditions for number of filled grains/panicle

\begin{tabular}{lllllllll}
\hline Environments & LI & L2 & $L 3$ & $L 4$ & $L 5$ & $L 6$ & L7 & Mean \\
\hline R1 FPD Y1 & 202.0 & 177.33 & 212.63 & 200.15 & 215.28 & 155.30 & 155.30 & 188.28 \\
R1 SPD Y1 & 197.88 & 171.80 & 198.77 & 207.14 & 210.99 & 164.0 & 138.59 & 184.16 \\
R1 FPD Y2 & 198.54 & 168.0 & 200.0 & 210.0 & 208.14 & 142.33 & 160.0 & 183.85 \\
R1 SPD Y2 & 187.0 & 161.80 & 205.23 & 204.55 & 205.60 & 138.23 & 149.57 & 178.85 \\
R2 FPD Y1 & 191.33 & 155.38 & 215.72 & 209.28 & 197.17 & 152.0 & 143.55 & 180.63 \\
R2 SPD Y1 & 192.84 & 165.60 & 199.49 & 199.12 & 218.55 & 148.70 & 171.04 & 185.04 \\
R2 FPD Y2 & 200.0 & 170.44 & 203.83 & 205.37 & 220.0 & 132.55 & 181.22 & 187.63 \\
R2 SPD Y2 & 186.23 & 173.18 & 200.66 & 201.28 & 182.44 & 162.43 & 133.37 & 177.08 \\
R3 FPD Y1 & 190.0 & 169.50 & 207.54 & 206.77 & 170.18 & 150.27 & 151.77 & 178.0 \\
R3 SPD Y1 & 185.68 & 179.54 & 219.73 & 214.33 & 205.38 & 147.27 & 142.57 & 184.92 \\
R3 FPD Y2 & 190.28 & 158.36 & 215.66 & 195.17 & 211.0 & 138.69 & 148.0 & 179.59 \\
R3 SPD Y2 & 179.54 & 178.0 & 211.35 & 190.83 & 208.37 & 147.80 & 146.97 & 180.40 \\
Mean & $\mathbf{1 9 1 . 7 7}$ & 169.07 & $\mathbf{2 0 7 . 5 5}$ & $\mathbf{2 0 3 . 6 6}$ & $\mathbf{2 0 4 . 4 2}$ & 148.29 & 151.82 & 182.36 \\
\hline
\end{tabular}

bands were polymorphic with $66.33 \%$ (polymorphism) as shown in Fig. 1 (Table 16). The average number of polymorphic ISSR markers was 11.16 fragments for each primer. The number of fragments was in the range of 13-23 and molecular size was in the range of $238-2225$ bp.

The highest number of polymorphic bands (19 bands) were observed in 17898-A primer, followed by 844-B primer (17 bands), 17898-B primer (11 bands), and the two primers 17899-B and HB-12 (eight fragments each), while the lowest number of polymorphic bands (4 bands) was shown in the 17899-A primer.

The highest unique bands or positive specific marker (10) and highest polymorphism percentage (82.61\%) appeared in primer 17898-A where it recorded the highest polymorphic bands (19), while that, 17899-A and
17898-B primers were exhibited the lowest number of unique bands or positive marker (1) and lowest polymorphism percentage $(30.76 \%)$ only for 17899 -A primer. The final results showed 24 positive and 5 negative specific markers which were considered as molecular guides to compare among the recently identified genotypes (Table 17 (Fig 2). In this regard, it will be presented for example not limited some results such as primer 17898-B revealed one positive marker only with size 972 bp for L6. While the primer 17899-B showed four positive markers with sizes 1537, 547, 361, and $317 \mathrm{bp}$ where the molecular sizes 1537, 361, and $317 \mathrm{bp}$ were specific for L1 and the molecular size at 547 bp was observed for L7, the same primer exhibited two negative markers with sizes 353 and 238 bp for L1 and L6. In addition, primer HB-12 exhibited three

Table 9 The mean values for the seven rice entries under the 12 environments for grain yield/plant

\begin{tabular}{|c|c|c|c|c|c|c|c|c|}
\hline Environments & $\mathrm{LI}$ & $\mathrm{L} 2$ & L3 & $\llcorner 4$ & $\mathrm{L} 5$ & L6 & L7 & Mean \\
\hline R1 FPD Y1 & 76.33 & 59.38 & 86.13 & 72.03 & 55.87 & 35.94 & 33.28 & 59.85 \\
\hline (R1 SPD Y1 & 84.0 & 45.07 & 79.80 & 58.89 & 82.30 & 48.03 & 39.40 & 62.49 \\
\hline R1 FPD Y2 & 85.73 & 39.77 & 87.33 & 83.06 & 72.39 & 55.16 & 37.56 & 65.85 \\
\hline R1 SPD Y2 & 69.69 & 48.64 & 80.74 & 75.49 & 67.08 & 39.40 & 42.19 & 60.46 \\
\hline R2 FPD Y1 & 88.0 & 51.50 & 78.37 & 68.37 & 65.47 & 38.33 & 50.55 & 62.94 \\
\hline R2 SPD Y1 & 72.88 & 57.38 & 83.42 & 70.27 & 80.22 & 41.66 & 48.37 & 64.88 \\
\hline R2 FPD Y2 & 81.44 & 53.05 & 75.77 & 63.97 & 59.82 & 32.33 & 60.53 & 60.98 \\
\hline R2 SPD Y2 & 89.59 & 62.08 & 89.35 & 88.50 & 69.85 & 49.68 & 29.48 & 68.36 \\
\hline R3 FPD Y1 & 78.62 & 65.34 & 81.48 & 84.38 & 75.73 & 51.29 & 38.33 & 67.88 \\
\hline R3 SPD Y1 & 80.71 & 50.12 & 76.83 & 65.33 & 89.16 & 47.28 & 42.17 & 64.51 \\
\hline R3 FPD Y2 & 66.14 & 55.33 & 62.80 & 82.17 & 80.33 & 34.21 & 44.39 & 60.76 \\
\hline R3 SPD Y2 & 75.36 & 64.11 & 84.60 & 79.55 & 71.93 & 58.0 & 37.12 & 67.23 \\
\hline Mean & 79.04 & 54.31 & 80.55 & 74.33 & 72.51 & 44.27 & 41.94 & 63.85 \\
\hline
\end{tabular}


Table $\mathbf{1 0}$ The mean values for the seven rice entries under the 12 environments for flag leaf area

\begin{tabular}{lllllllll}
\hline Environments & $L 1$ & $L 2$ & $L 3$ & $L 4$ & $L 5$ & $L 6$ & $L 7$ & Mean \\
\hline R1 FPD Y1 & 51.28 & 22.31 & 69.32 & 72.28 & 42.91 & 39.05 & 42.36 & 48.50 \\
R1 SPD Y1 & 44.15 & 28.05 & 71.40 & 57.31 & 77.50 & 31.50 & 27.45 & 48.19 \\
R1 FPD Y2 & 40.67 & 30.32 & 60.84 & 45.06 & 28.33 & 33.77 & 57.18 & 42.31 \\
R1 SPD Y2 & 39.48 & 28.25 & 58.60 & 73.24 & 53.80 & 29.88 & 40.31 & 46.22 \\
R2 FPD Y1 & 50.84 & 19.77 & 49.12 & 55.16 & 78.20 & 35.42 & 50.18 & 48.38 \\
R2 SPD Y1 & 38.82 & 21.37 & 45.56 & 56.18 & 56.80 & 42.05 & 36.77 & 42.50 \\
R2 FPD Y2 & 55.38 & 24.27 & 50.39 & 38.58 & 46.29 & 27.77 & 59.60 & 43.18 \\
R2 SPD Y2 & 49.63 & 48.55 & 63.38 & 73.94 & 59.78 & 38.16 & 42.16 & 53.65 \\
R3 FPD Y1 & 37.99 & 63.88 & 52.17 & 75.03 & 63.17 & 40.15 & 38.27 & 52.95 \\
R3 SPD Y1 & 43.29 & 58.29 & 57.44 & 58.0 & 81.05 & 32.87 & 40.28 & 53.03 \\
R3 FPD Y2 & 62.07 & 60.37 & 39.58 & 53.07 & 47.83 & 28.40 & 29.88 & 45.88 \\
R3 SPD Y2 & 34.39 & 52.28 & 71.19 & 48.18 & 60.44 & 49.53 & 33.90 & 49.98 \\
Mean & $\mathbf{4 5 . 6 6}$ & 38.14 & $\mathbf{5 7 . 4 1}$ & $\mathbf{5 8 . 8 3}$ & $\mathbf{5 8 . 0}$ & 35.71 & 41.52 & 47.89 \\
\hline
\end{tabular}

positive markers at molecular sizes 642,461 , and 427 bp for L6, L2, and L1 beside one negative marker with size 826 bp for L5, respectively, and so on.

\section{Proximity matrix analysis (genetic similarity)}

The data presented in Table 18 showed 21 pairwise comparisons to discuss the genetic relationships among the seven promising rice entries revealed in terms of similarity and these results also showed within the data obtained in Fig. 3. ISSR markers used to figure out the relationships among the seven rice genotypes through using UPGMA of the dendrogram or phylogenetic tree in addition, the proximity matrix to identify all possible genetic similarities.. The genetic similarity was in the range of $0.50-0.739$ with an average of 0.619 , where the minimum value of similarity was 0.50 among the lines L2 and L6, while the maximum value of similarity was 0.739 within L6 and L7. In the same regard, the second category of high genetic similarity data, for example, were observed between some rice lines relationships such as L1 and L2, L2 and L3, and L5 and L6, where the values were 0.707, 0.727, and 0.724 , respectively.

\section{Cluster analysis (phylogenetic tree)}

The results of the dendrogram obtained from UPGMA cluster analysis showed that the seven rice lines could be divided into two main clusters (Fig. $3)$. The first cluster included L1 only and one sub-cluster included L2 and L3. The second cluster divided into two sub-clusters: the first one contained line numbers L4 and L5; and the second sub-cluster included L6 and L7.

\section{Discussion}

This investigation discussed the genetic stability of seven promising rice entries under 12 Egyptian environments and already succeeded in determining two trends of genetic stability for previous rice genotypes. These results confirming the germplasm of materials studied were very severally about their performance from season to season, region to region and from sowing date to else one. From the data obtained by mean squares related to the environment factors (Linear) and environment $\mathrm{X}$ genotypes (Linear), it could be concluded that the results of the stability analysis revealed highly significant variances for all traits calculated punctually in this track which indicated that the variations within all environments factors (locations, years, and treatments) detected high considerable leverage on all entries and studied traits and the evidence of these investigations showed the mean squares of the two linear forms for all traits were not only highly significant differences but also higher than non-linear components. This boosted the prospect of high yield for rice lines and risingly settled under different environmental statuses. The variations generated from mean squares related with environments and genotype $\mathrm{X}$ environments were shown as highly significant for all estimated traits which confirmed the considerable interaction of all genotypes under different environmental conditions of seasons, regions, and treatments in different

Table 11 The mean values obtained from the seven rice lines under all environments for all studied traits

\begin{tabular}{llllllll}
\hline Entries & $\begin{array}{l}\text { Plant height } \\
(\mathrm{cm})\end{array}$ & $\begin{array}{l}\text { Heading date } \\
\text { (day) }\end{array}$ & $\begin{array}{l}\text { 1000-grain weight } \\
(\mathrm{gm})\end{array}$ & $\begin{array}{l}\text { Number of panicles/ } \\
\text { plant }\end{array}$ & $\begin{array}{l}\text { Number of filled grains/ } \\
\text { panicle }\end{array}$ & $\begin{array}{l}\text { Grain yield/plant } \\
(\mathrm{gm})\end{array}$ & $\begin{array}{l}\text { Flag leaf area } \\
\left(\mathrm{cm}^{2}\right)\end{array}$ \\
\hline L1 & $\mathbf{8 9 . 3 6}$ & $\mathbf{9 1 . 6 7}$ & $\mathbf{3 2 . 2 0}$ & $\mathbf{3 3 . 0 4}$ & $\mathbf{1 9 1 . 7 7}$ & $\mathbf{7 9 . 0 4}$ & $\mathbf{4 5 . 6 6}$ \\
L2 & 106.48 & 106.10 & 26.37 & 29.40 & 169.07 & 54.31 & 38.14 \\
L3 & $\mathbf{1 0 1 . 1 0}$ & $\mathbf{9 1 . 2 1}$ & $\mathbf{3 6 . 1 4}$ & $\mathbf{3 7 . 0 1}$ & $\mathbf{2 0 7 . 5 5}$ & $\mathbf{8 0 . 5 5}$ & $\mathbf{5 7 . 4 1}$ \\
L4 & $\mathbf{9 9 . 7 0}$ & $\mathbf{1 0 4 . 3 9}$ & $\mathbf{3 5 . 2 3}$ & $\mathbf{3 6 . 1 4}$ & $\mathbf{2 0 3 . 6 6}$ & $\mathbf{7 4 . 3 3}$ & $\mathbf{5 8 . 8 3}$ \\
L5 & $\mathbf{9 0 . 3 2}$ & $\mathbf{8 8 . 7 6}$ & $\mathbf{3 5 . 4 5}$ & $\mathbf{3 2 . 8 9}$ & $\mathbf{2 0 4 . 4 2}$ & $\mathbf{7 2 . 5 1}$ & $\mathbf{5 8 . 0}$ \\
L6 & 102.45 & 108.16 & 25.53 & 26.12 & 148.29 & 44.27 & 35.71 \\
L7 & 101.41 & 110.01 & 26.96 & 26.58 & 151.82 & 41.94 & 41.52 \\
\hline
\end{tabular}


Table 12 The mean performances for all studied traits of the seven rice entries under all environments

\begin{tabular}{|c|c|c|c|c|c|c|c|}
\hline Environments & $\begin{array}{l}\text { Plant height } \\
(\mathrm{cm})\end{array}$ & $\begin{array}{l}\text { Heading date } \\
\text { (day) }\end{array}$ & $\begin{array}{l}\text { 1000-grain weight } \\
\text { (gm) }\end{array}$ & $\begin{array}{l}\text { Number of } \\
\text { panicles/plant }\end{array}$ & $\begin{array}{l}\text { Number of filled grains/ } \\
\text { panicle }\end{array}$ & $\begin{array}{l}\text { Grain yield/plant } \\
(\mathrm{gm})\end{array}$ & $\begin{array}{l}\text { Flag leaf area } \\
\left(\mathrm{cm}^{2}\right)\end{array}$ \\
\hline R1 FPD Y1 & 98.24 & 101.58 & 31.68 & 31.49 & 188.28 & 59.85 & 48.50 \\
\hline R1 SPD Y1 & 95.93 & 100.32 & 29.79 & 31.44 & 184.16 & 62.49 & 48.19 \\
\hline R1 FPD Y2 & 96.92 & 101.82 & 31.70 & 30.45 & 183.85 & 65.85 & 42.31 \\
\hline R1 SPD Y2 & 99.58 & 99.64 & 29.57 & 31.16 & 178.85 & 60.46 & 46.22 \\
\hline R2 FPD Y1 & 99.39 & 99.61 & 31.70 & 30.65 & 180.63 & 62.94 & 48.38 \\
\hline R2 SPD Y1 & 98.39 & 100.12 & 32.32 & 30.64 & 185.04 & 64.88 & 42.50 \\
\hline R2 FPD Y2 & 99.75 & 99.82 & 32.21 & 33.10 & 187.63 & 60.98 & 43.18 \\
\hline R2 SPD Y2 & 98.06 & 100.45 & 31.67 & 31.26 & 177.08 & 68.36 & 53.65 \\
\hline R3 FPD Y1 & 100.80 & 98.98 & 30.67 & 30.68 & 178.0 & 67.88 & 52.95 \\
\hline R3 SPD Y1 & 99.51 & 100.36 & 31.28 & 33.80 & 184.92 & 64.51 & 53.03 \\
\hline R3 FPD Y2 & 98.96 & 100.36 & 29.82 & 32.54 & 179.59 & 60.76 & 45.88 \\
\hline R3 SPD Y2 & 98.75 & 97.46 & 31.09 & 31.97 & 180.40 & 67.23 & 49.98 \\
\hline Mean & 98.69 & 100.04 & 31.12 & 31.59 & 182.36 & 63.85 & 47.89 \\
\hline
\end{tabular}

years. Results obtained from variances due to lines were viewed as highly significant for all the estimated traits versus collected perversion which confirmed the turnout of appropriate genetic divergence among the entries. In addition, the overall difference for all entries and environments used in the 12 experiments or environments also confirmed high genetic stability for these lines from one experiment to another. These results agree with the authors Gill and Kumar (1989), Popovic et al. (2013), Selvi et al. (2015), Hamawaki et al. (2015), Akter et al. (2015), Silva et al. (2016), and El-Mouhamady et al. (2017). After listing the most important results obtained in Tables 4, 5, 6, 7, 8, $9,10,11$ and 12 from the analysis of genetic stability, it can be said that the seven lines of rice under study have proved their high genetic stability with unrivaled form under all environments. This was verified after testing the yield and its components which included the seven lines containing two trends of genetic stability where the first level contained the entry numbers 1 , 3,4 , and 5 and the second level included the line numbers 2, 6, and 7. Similar results agreed with those obtained by the authors Hossian et al. (2003), Kumar et al. (2009), Karnataka (2011), Mosavi et al. (2012), Lakew et al. (2014), Seyou et al. (2016), Ajmera et al. (2017), and Sadimantara et al. (2018). All these scientists agreed on the importance of genetic stability with high value and the efficiency associated with high yield and widespread environmental acclimatization.

The results of stability parameter bi may be indicated by the damaging of the genetic stability and the ambit of acclimating for these lines under various types of conditions beside, this diverse may be alteration from line to line according to the kind of this environment conditions, while the $S^{2}$ di parameter results revealed the optimum values for the highest entries for genetic stability and showed the better mean values for all studied traits under the 12 experiments, so the lines $1,3,4$, and 5 came in the first rank for highly genetic stability under any conditions for the 12 environments, while the line numbers 2, 6, and 7 exhibited the second track in this regard (Table 13) (El-Mouhamady et al. 2017). Results of $R^{2}$ showed that the lines number $(1,3,4$, and 5) were recorded highly genetically stable under all conditions particularly with better agricultural administration. This steadiness reverberates the gauge of genetic and environmental readjust mention entertained these rice genotypes. The rest of rice lines were coming in the second rank of genetic stability depending on the results of stability analysis \%. It should be noted that some of the important points in this study are that these seven lines, especially the four top ones in terms of degree and high level of genetic stability, respectively (lines $1,3,4$, and 5), are highly yielding, advanced and had positive results in all studied environments. This is evident in the six above-mentioned superior environments where the yield and its components were high for all studied entries especially in the environmental conditions mentioned above (Table 14). In another context, these entries have significantly exceeded adverse environmental conditions such as high salinity tolerance, high levels of heavy metals, steady temperature increase, and ideal resistance levels in many diseases which infects the yield of rice, such as bread and roasted seeds. It also gives a high response to the utilization of the nitrogen element during agriculture. These 


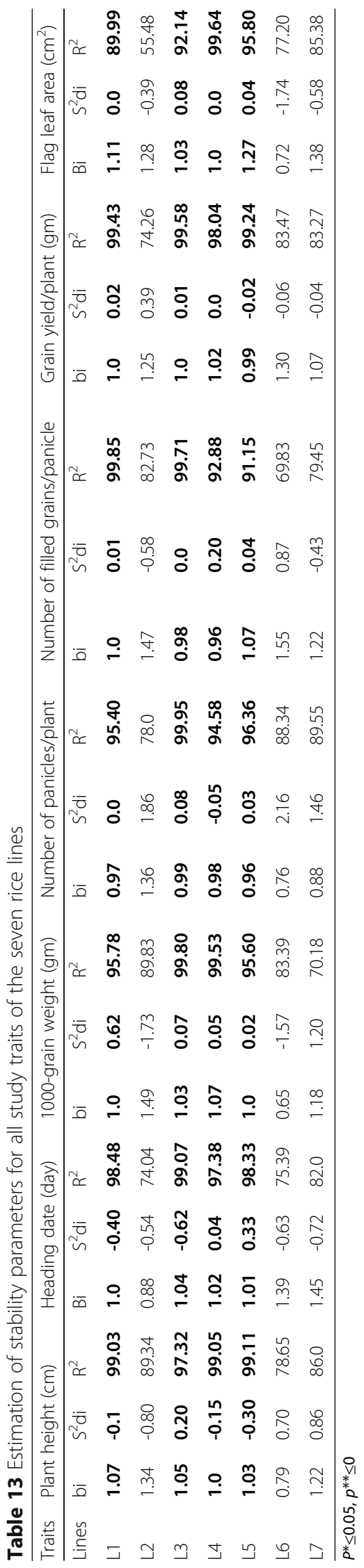




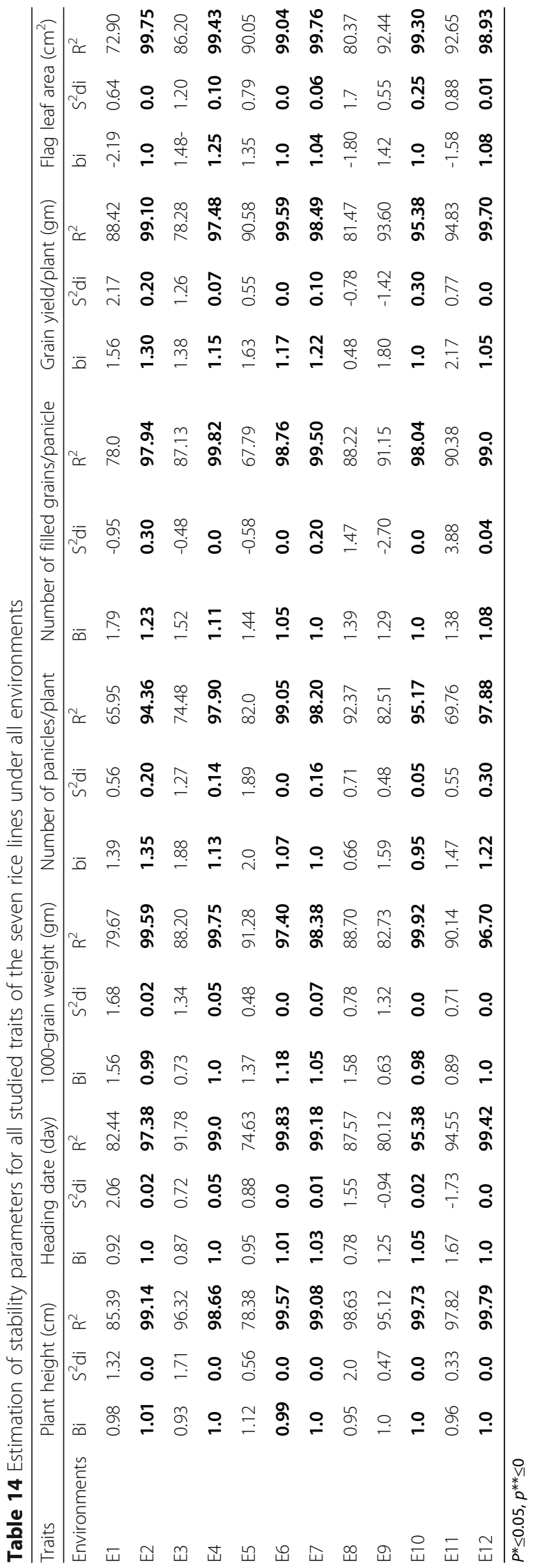


Table 15 Genotypic $(\delta 2 \mathrm{~g})$, phenotypic ( $\delta 2 \mathrm{ph})$, error variances $(\delta 2 \mathrm{e})$, heritability $\left(\mathrm{H}^{2}\right)$ in the broad sense: genotypic (G.C.V.) and phenotypic (P.C.V.) coefficients of variation evaluated for seven traits of rice lines

\begin{tabular}{|c|c|c|c|c|c|c|c|}
\hline Traits & Mean & $\begin{array}{l}\text { Genotypic variation } \\
\left(\delta^{2} \mathrm{~g}\right)\end{array}$ & $\begin{array}{l}\text { Phenotypic variation } \\
\left(\delta^{2} p h\right)\end{array}$ & $\begin{array}{l}\text { Error variation } \\
\left(\delta^{2} e\right) \\
\text { (pooled error) }\end{array}$ & $\begin{array}{l}\text { Heritability }\left(\mathrm{H}^{2} \mathrm{~b}\right. \\
\%)\end{array}$ & $\begin{array}{l}\text { G.C.V. } \\
(\%)\end{array}$ & $\begin{array}{l}\text { P.C.V. } \\
\text { (\%) }\end{array}$ \\
\hline Plant height (cm) & 98.69 & 5.24 & 5.89 & 0.65 & 88.96 & 23.04 & 24.42 \\
\hline Heading date (day) & 100.04 & 4.46 & 4.74 & 0.28 & 94.09 & 21.11 & 21.76 \\
\hline 1000-grain weight (gm) & 31.12 & 5.64 & 7.33 & 1.69 & 76.94 & 42.57 & 48.53 \\
\hline Number of panicles/plant & 31.59 & 7.15 & 9.83 & 2.68 & 72.73 & 47.57 & 55.78 \\
\hline $\begin{array}{l}\text { Number of filled grains/ } \\
\text { panicle }\end{array}$ & 182.36 & 3.53 & 4.36 & 0.83 & 80.96 & 13.91 & 15.46 \\
\hline Grain yield/plant (gm) & 63.85 & 6.71 & 8.14 & 1.43 & 82.43 & 32.41 & 35.70 \\
\hline Flag leaf area $\left(\mathrm{cm}^{2}\right)$ & 47.89 & 3.02 & 3.75 & 0.73 & 80.53 & 25.11 & 27.98 \\
\hline
\end{tabular}

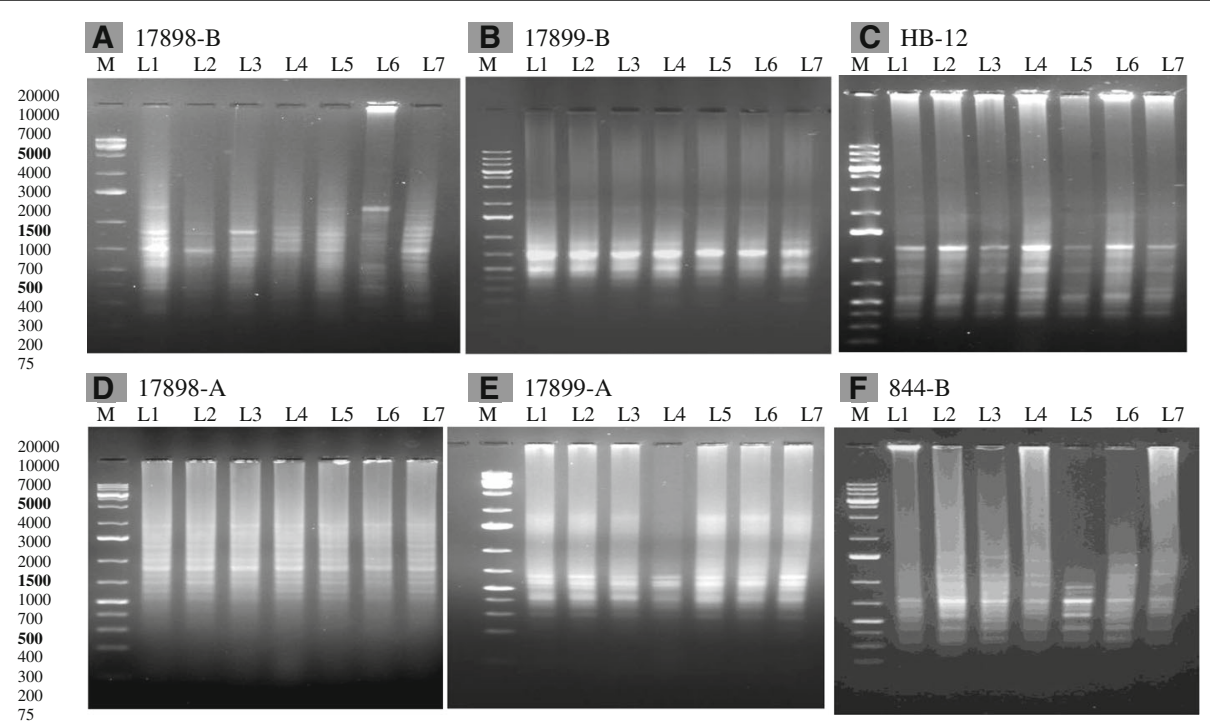

Fig. 1 The inter-simple sequence repeats (ISSR) amplification pattern obtained for seven rice lines: a primer 17898-B, b primer 17899-B, c primer 17899-B, d primer 17898-A, e primer 17899-A, and $\mathbf{f}$ primer 844-B

Table 16 Band variation and polymorphism percentage in seven rice lines

\begin{tabular}{|c|c|c|c|c|c|c|c|c|}
\hline Primers & $\begin{array}{l}\text { Total } \\
\text { bands }\end{array}$ & $\begin{array}{l}\text { Molecular } \\
\text { size (bp) }\end{array}$ & $\begin{array}{l}\text { Number of } \\
\text { monomorphic }\end{array}$ & $\begin{array}{l}\text { Number of unique bands } \\
\text { (positive marker) }\end{array}$ & $\begin{array}{l}\text { Number of } \\
\text { polymorphic }\end{array}$ & $\begin{array}{l}\text { Polymorphism } \\
\text { (\%) }\end{array}$ & Sequence & $\begin{array}{l}\text { Annealing } \\
\left({ }^{\circ} \mathrm{C}\right)\end{array}$ \\
\hline $\begin{array}{l}17898- \\
B\end{array}$ & 15 & $473-1832$ & 4 & 1 & 11 & 73.33 & $\begin{array}{l}5^{\prime}-(C A) 6 \\
\text { GT-3' }\end{array}$ & 40 \\
\hline $\begin{array}{l}17899- \\
B\end{array}$ & 13 & $238-2225$ & 5 & 4 & 8 & 61.538 & $\begin{array}{l}5^{\prime}-(C A) 6 \\
\text { GG-3' }\end{array}$ & 41 \\
\hline HB-12 & 15 & $390-1140$ & 7 & 3 & 8 & 53.333 & $\begin{array}{l}5^{\prime}-(C A C) 3 \\
G C-3^{\prime}\end{array}$ & 40 \\
\hline $\begin{array}{l}17898- \\
A\end{array}$ & 23 & 496-2034 & 4 & 10 & 19 & 82.609 & $\begin{array}{l}5^{\prime}-(C A) 6 \\
A C-3^{\prime}\end{array}$ & 38 \\
\hline $\begin{array}{l}17899- \\
A\end{array}$ & 13 & 293-1860 & 9 & 1 & 4 & 30.769 & $\begin{array}{l}5^{\prime}-(C A) 6 \\
A G-3^{\prime}\end{array}$ & 38 \\
\hline $844-B$ & 22 & 335-1992 & 5 & 5 & 17 & 77.273 & $\begin{array}{l}5^{\prime}-(C T) 8 \\
G C-3^{\prime}\end{array}$ & 45 \\
\hline Total & 101 & $238-2225$ & 34 & 24 & 67 & 66.33 & & \\
\hline
\end{tabular}


Table 17 Positive (P) and negative (N) specific markers of the seven rice entries using six ISSR primers

\begin{tabular}{|c|c|c|c|c|c|c|c|c|c|}
\hline ISSR primers & MS (bp) & L1 & L2 & L3 & L4 & $\mathrm{L} 5$ & L6 & L7 & MT (P or N) \\
\hline 17898-B & 972 & - & - & - & - & - & + & - & $P(L 6)$ \\
\hline \multirow[t]{6}{*}{ 17899-B } & 1537 & + & - & - & - & - & - & - & $P(L 1)$ \\
\hline & 547 & - & - & - & - & - & - & + & $P(L 7)$ \\
\hline & 361 & + & - & - & - & - & - & - & $P(L 1)$ \\
\hline & 353 & - & + & + & + & + & + & + & $N(L 1)$ \\
\hline & 317 & + & - & - & - & - & - & - & $P(L 1)$ \\
\hline & 238 & + & + & + & + & + & - & + & $N(L 6)$ \\
\hline \multirow[t]{4}{*}{ HB-12 } & 826 & + & + & + & + & - & + & + & N (L5) \\
\hline & 642 & - & - & - & - & - & + & - & $P(L 6)$ \\
\hline & 461 & - & + & - & - & - & - & - & $P(L 2)$ \\
\hline & 427 & + & - & - & - & - & - & - & $P(L 1)$ \\
\hline \multirow[t]{12}{*}{ 17898-A } & 1657 & - & - & - & - & + & - & - & P (L5) \\
\hline & 1492 & - & - & - & + & - & - & - & $P(L 4)$ \\
\hline & 1215 & - & - & - & + & - & - & - & $P(L 4)$ \\
\hline & 1153 & - & - & - & - & - & - & + & $P(L 7)$ \\
\hline & 1133 & - & - & - & + & - & - & - & $P(\llcorner 4)$ \\
\hline & 1056 & + & + & + & + & + & + & - & N (L7) \\
\hline & 1024 & - & - & - & - & - & - & + & $P(L 7)$ \\
\hline & 788 & + & + & + & + & - & + & + & N (L5) \\
\hline & 778 & - & - & - & - & + & - & - & $P(L 5)$ \\
\hline & 665 & - & - & + & - & - & - & - & $P(L 3)$ \\
\hline & 642 & - & - & - & - & - & - & + & $P(L 7)$ \\
\hline & 496 & + & - & - & - & - & - & - & $P(L 1)$ \\
\hline 17899-A & 795 & - & - & - & - & - & + & - & P (L6) \\
\hline \multirow[t]{5}{*}{ 844-B } & 803 & - & - & - & - & + & - & - & P (L5) \\
\hline & 786 & - & - & + & - & - & - & - & $P(L 3)$ \\
\hline & 750 & - & + & - & - & - & - & - & $P(L 2)$ \\
\hline & 556 & - & - & - & - & - & - & + & $P(L 7)$ \\
\hline & 544 & - & - & - & + & - & - & - & $P(L 4)$ \\
\hline Range & $317-1657$ & - & - & - & - & - & - & - & \\
\hline Total & - & 5 & 2 & 2 & 4 & 3 & 3 & 5 & $24 P+5 N$ \\
\hline
\end{tabular}

Table 18 Genetic similarity matrix between seven rice entries with ISSR markers based on Jaccard coefficients

\begin{tabular}{llllllll}
\hline & $\mathrm{L} 1$ & $\mathrm{~L} 2$ & $\mathrm{~L} 3$ & $\mathrm{~L} 4$ & $\mathrm{~L} 5$ & $\mathrm{~L} 6$ & $\mathrm{L7}$ \\
\hline $\mathrm{L1}$ & 1 & & & & & & \\
$\mathrm{~L} 2$ & 0.70769 & 1 & & & & & \\
$\mathrm{~L} 3$ & 0.59155 & 0.72727 & 1 & & & & \\
$\mathrm{~L} 4$ & 0.58571 & 0.62319 & 0.67647 & 1 & & & \\
$\mathrm{~L} 5$ & 0.52703 & 0.52 & 0.65714 & 0.70149 & 1 & & \\
$\mathrm{L6}$ & 0.50649 & 0.5 & 0.60811 & 0.60274 & 0.72464 & 1 & \\
$\mathrm{L7}$ & 0.56164 & 0.51316 & 0.58108 & 0.64286 & 0.64789 & 0.73913 & 1 \\
\hline
\end{tabular}

entries can be considered promising lines to be adopted as commercial varieties may be distributed at the level of the republic depending on all results of genetic stability analysis, as well as clearly used in breeding programs by transferring resistance genes to sensitive local varieties for high salinity and other stresses.. Similar results were in agreement with those obtained by other authors Hossian et al. (2003), Kumar et al. (2009), Karnataka (2011), Mosavi et al. (2012), Lakew et al. (2014), Seyou et al. (2016), Ajmera et al. (2017), El-Mouhamady et al. (2017), and Sadimantara et al. (2018). The results related to genetic components confirmed that the effect of genotypic variance was higher than the effect of environmental variance. In addition, the biggest section of variance was genotypic variance and the controlling and inheriting for all traits being studied would depend greatly on genetic variance. The previous data in Table 15 indicated unequivocally that the environmental impact was lacking in the inheritance of the studied traits mentioned above and confirm scientifically and practically the extent of genetic stability enjoyed by the seven rice entries under investigation, which was achieved significantly after these lines gave positive and concrete results during the evaluation of yield and its components traits in
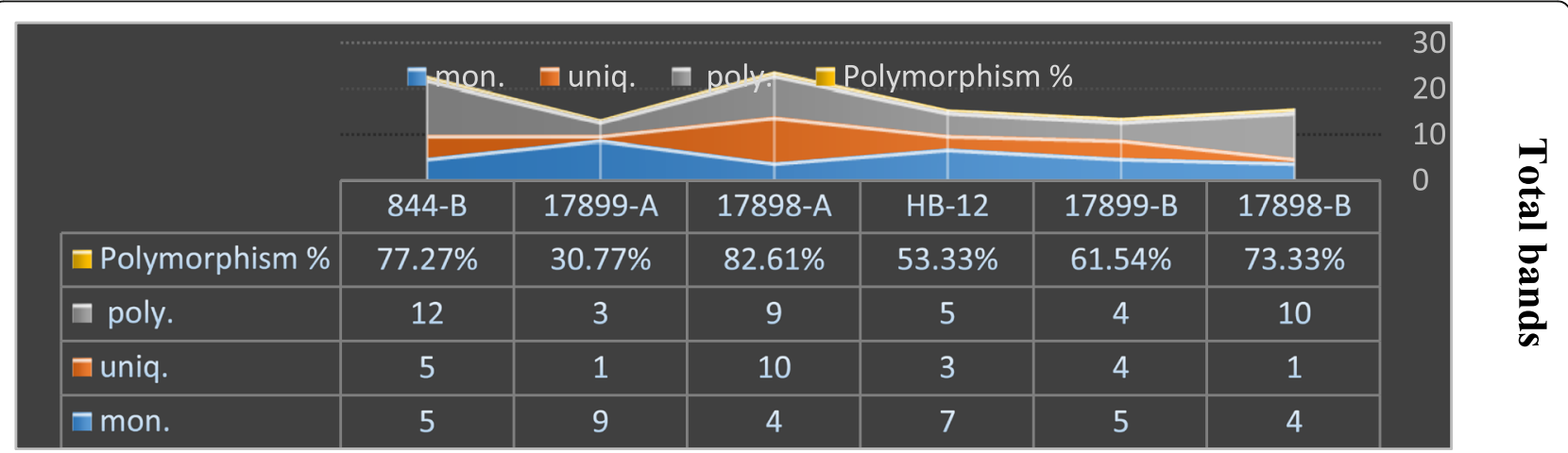

Fig. 2 The relationship between total bands and monomorphic, unique, polymorphic, and polymorphism percentage of six ISSR primers used for detection of seven rice lines 


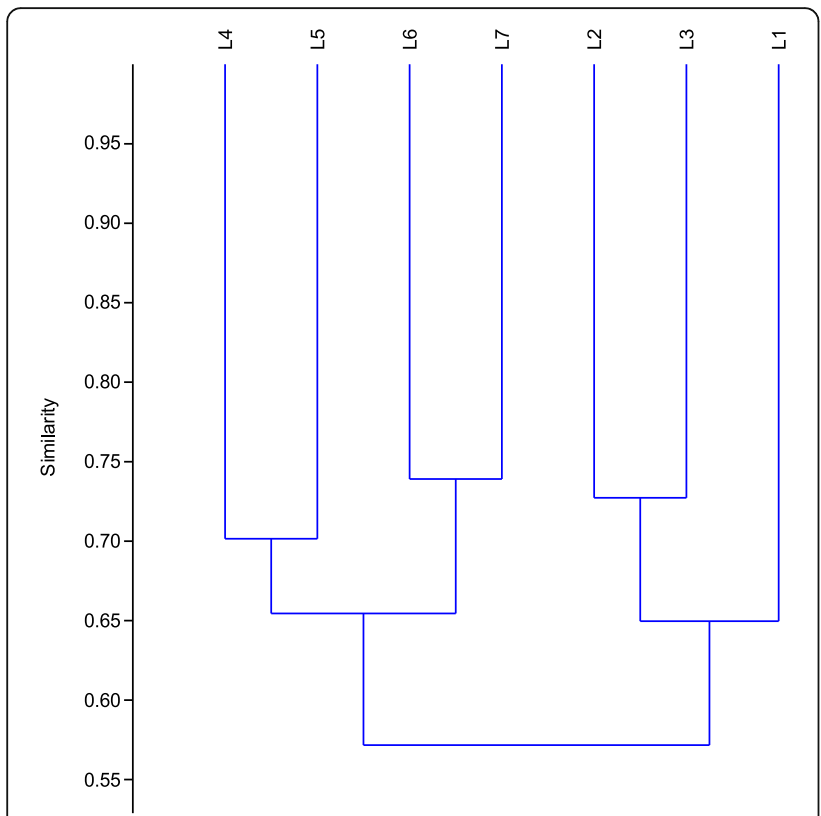

UPGMA

Nei-Li's similarity coefficient

Fig. 3 Dendrogram representing the genetic relationship among the seven rice lines using UPGMA cluster analysis of Nei-Li's similarity coefficient generated from ISSR markers

the 12 environmental experiments. Any future change will be reviewed for environmental impact and will also be non-existent. Similar results were in agreement with those reported by Ajmera et al. (2017), El-Mouhamady et al. (2017), Sadimantara et al. (2018), and Neng et al. (2018). Molecular genetics has succeeded in comparing and clarifying these promising rice entries and has made clear the most important molecular differences between the different entries. The six ISSR primers were successfully used to determine the molecular differences among the seven rice genotypes by generating 67 polymorphic bands, of which 24 were positive and 5 were negative specific markers. (Tables 16 and 17). The results in Table 18 showed that the rice numbers $2,5,6$, and 7 were treating as the major guides of genetic purity and stability because they showed unparalleled genetic similarity between them on examination. These accessions are considered very important in plant-breeding programs to transfer genes responsible for the tolerance of high salinity and resistance to diseases as well as high yield to sensitive cultivars for these environmental stresses through hybridization, as well as it can agriculture and give a high yield in various regions of the republic. Cluster analysis also helped to draw a clear picture of the extent of genetic stability; relationships enjoyed these previous entries which demonstrated the great genetic stability of these lines. These results agreed with those reported by groups of scientists such as Al-Turki and Basahi (2015), Esmail et al. (2016), El-Mouhamady et al. (2016), Ramadan et al. (2016), Khatab et al. (2017), Dharmaraj et al. (2018), and Iqbal et al. (2018).

One of the most important recommendations of this study is the cultivation of the seven superior rice lines which have a lot of varieties suitable for the different conditions or environments in Egypt. The seven rice lines are proven to be remarkably superior in terms of genetic stability because of their high yield, tolerance to high salinity levels in soils, and resistance to various diseases.

\section{Conclusion}

The present investigation was conducted to discuss the genetic stability on seven promising lines of rice under 12 different environments through estimating agro-morphological traits; all parameters were ob-tained from the stability analysis besides using six ISSR primers to compare the previous genotypes. The final results revealed that the line numbers $1,3,4$, and 5 showed high genetic stability under all experiments and came in top in this regard. Lines 2, 6, and 7 also recorded high genetic stability and came in second and are available for growing in different locations.

\section{Abbreviations}

bi: Regression coefficient; E1: (R1 FPD Y1); E10: (R3 SPD Y1); E11: (R3 FPD Y2); E12: (R3 SPD Y2); E2: (R1 SPD Y1); E3: (R1 FPD Y2); E4: (R1 SPD Y2); E5: (R2 FPD Y1); E6: (R2 SPD Y1); E7: (R2 FPD Y2); E8: (R2 SPD Y2); E9: (R3 FPD Y1);

FPD: First planting date; ISSR: Inter-Simple Sequence Repeat Markers; L1: (Sakha 101 X Giza 178); L2: (Agami X Giza 177); L3: (GZ1368-S-5-4 X Giza 177); L4: (Gaori X Sakha 104); L5: (Gaori X GZ1368-S-5-4); L6: (Gaori X Sakha 104); L7: (Sakha 104 X Giza 182); Mon: Monomorphic band;

Poly: Polymorphism bands; R1: Region 1; R2: Region 2; R2: The percentage of stability; R3: Region 3; S2di: Deviation from regression; SPD: Second planting date; Uniq: Unique band; Y1: Year 1; Y2: Year 2

\section{Acknowledgements \\ Not applicable.}

Funding

Not applicable.

\section{Availability of data and materials}

The datasets used and/or analyzed during the current study are available from the corresponding author on reasonable request.

\section{Authors' contributions}

All authors wrote, read, and approved the final manuscript.

Ethics approval and consent to participate

Not applicable.

Consent for publication

Not applicable.

Competing interests

The authors declare that they have no competing interests. 


\section{Publisher's Note}

Springer Nature remains neutral with regard to jurisdictional claims in published maps and institutional affiliations.

Received: 27 February 2019 Accepted: 20 March 2019

Published online: 29 May 2019

\section{References}

Ajmera S, Kumar SS, Ravindrababu V (2017) Studies on stability analysis for grain yield and its attributes in rice (Oryza sativa L.) genotypes. Int J Pure App Biosci 5(4):892-908

Akter A, Hasan MJ, Kulsum MU et al (2015) Genotype × Environment interaction and yield stability analysis in hybrid rice (Oryza sativa L.) By AMMI Biplot. Bangladesh Rice J 19(2):79-86

Al-Turki TA, Basahi MA (2015) Assessment of ISSR based molecular genetic diversity of Hassawi rice in Saudi Arabia. Saudi J Bio Sci 22(5):591-599

Collins WW, Wilson LG, Arrendell S et al (1987) Genotypexenvironment interaction in sweet potato yield and quality factors. J Amer Soc Hort Sci 112:579-589

Dharmaraj K, Ezhilkumar S, Dinesh R et al (2018) Studies on varietal identification of rice genotypes using ISSR markers. J Pharmacognosy Phytochemistry 7(SP1):2808-2812

Eberhart SA, Russell WA (1966) Stability parameters for comparing varieties. Crop Sci 6(1):36-40

Eldessouky EISS, Heiba AA, El-Mouhamady AA et al (2016) DNA Fingerprinting and half diallel analysis of some rice genotypes under water deficit conditions. Res J Pharmaceut Biol Chem Sci 7(4):985-997

El-Mouhamady AA, Abdel-Rahman HM, Elewa TA et al (2017) Molecular characterization and stability analysis for yield and its components traits in soybean (Glycine max L.). Int J Curr Microbiol App Sci 6(7):1835-1857

El-Mouhamady AA, El-Ashary ZM, Mohamed Fl et al (2016) Study the effect of water stress conditions on some genotypes of bread wheat (Triticum aestivum L.) based on morphological, physiological traits and DNA fingerprinting. Res J Pharma Biol Chem Sci 7(4):2065-2077

Esmail RM, Abdel Sattar AA, Abdel-samea NS et al (2016) Assessment of genetic parameters and drought tolerance indices in maize diallel crosses. Res $J$ Pharmaceut Biol Chem Sci 7(6):2409-2428

Fotokian MH, Agahi K (2014) Genetic worth and stability of selection indices in rice (Oryza sativa L.). Prog Biol Sci 4(2):153-166

Gill BS, Kumar JC (1989) Phenotypic stability in watermelon. Indian J Agri Sci 59: $145-148$

Hamawaki RL, Osvaldo TH, Ana PO et al (2015) Adaptability and stability analysis of soybean genotypes using tolerance and centroid methods. Am J Plant Sci 6:1509-1518

Heiba SAA, El-Mouhamady AA, Eldessouky SEl et al (2016) Study the genetic variations related to the resistance of heavy metals toxicity in some rice genotypes using RAPD markers. Int J Curr Microbiol App Sci 5(1):174-189

Hossian MA, Rahman L, Shamsuddin AKM (2003) Genotype-Environment interaction and stability analysis in soybean. J Biol Sci 3(11):1026-1031

Iqbal T, Hussain I, Ahmad N et al (2018) Genetic variability, correlation and cluster analysis in elite lines of rice. J Sci Agri 2:85-91

Jaccard P (1908) Nouvellesrecherchessur la distribution florale. Bull Soc Vaud Sci Nat 44:223-270

Kang MS, Magari R (1995) Stable a BASICA program for calculating stability and yield- stability statistics. Agron J 87(2):276-277

Karnataka J (2011) Stability analysis of puttabatta rice mutants. J Agric Sci 24(4): $527-528$

Kehr WR, Gardner CO (1960) Genetic variability in ranger alfalfa. Agron J 52:41-44 Khatab IA, El-Mouhamady AA, Abdel-Rahman HM et al (2017) Agromorphological and Molecular Characterization of Sorghum (Sorghum vulgare L.) for Water Stress Tolerance. Int J Curr Res Biosci Plant Biol 4(1):37-55

Kumar S, Bhandarkar S, Khan RU (2009) Studies on stability analysis in upland rice (Oryza sativa). Int J Agric Sci 5(1):180-181

Lakew T, Tariku S, Alem T et al (2014) Agronomic performances and stability analysis of upland rice genotypes in North West Ethiopia. Int J Sci Res Publ 4(4):1-9

Mosavi AA, Jelodar NB, Kazemitabar K (2012) Environmental responses and stability analysis for grain yield of some rice genotypes. Ann Bio Res 3(11): 5110-5113
Nanculao GD, Paredes M, Becerra V et al (2016) GGE biplot analysis of multienvironment yield trials of rice produced in a temperature climate. Chilean J Agric Res 76(2):152-157

Neng Z, Yongguang P, Yang H et al (2018) RAPD based genetic diversity analysis among wild and cultivated genotypes of Sarcandra glabra. Int J Bio Sci 12(2): $118-126$

Onyia VN, Okechukwu EC, Atugwu Al et al (2017) Genetic variability studies on twelve genotypes of rice (Oryza sativa L.) for growth and yield Performance in south eastern Nigeria. Not Sci Biol 9(1):110-115

Popovic V, Miladinovic J, Tatic M et al (2013) Stability of soybean yield and quality components. Afr J Agri Res 8(45):5651-5658

Ramadan WA, Abdel-Rahman HM, El-Mouhamady AA et al (2016) Molecular genetic studies on some barley entries for drought tolerance. Int J Pharm Tech Res 9(12):265-285

Sadimantara GR, Kadidaa B, Suaib et al (2018) Growth performance and yield stability of selected local upland rice genotypes in Buton Utara of Southeast Sulawesi. Int Conference Agric Environ Food Security 122:1-6. https:/doi.org/ 10.1088/1755-1315/122/1/012094

Selvi GSA, Kahani F, Hittalmani S (2015) Stability analysis of rice root QTL-NILs and pyramids for root morphology and grain yield. J Rice Res 3(4):1-8

Seyou M, Alamerew S, Bantte K (2016) Stability analysis of grain yield in rice genotypes across environments of Jimma Zone. Western Ethiopia. Journal of Cereals and Oilseeds 7(3):27-33

Silva KB, Bruzi AT, Zuffo AM et al (2016) Adaptability and phenotypic stability of soybean cultivars for grain yield and oil content. Genet Mol Res 15(2):1-11

Torres RO, Henry A (2018) Yield stability of selected rice breeding lines and donors across conditions of mild to moderately severe drought stress. Field Crop Res 220(5):37-45

Yassin TE (1973) Genotypic and phenotypic variances and correlations in field beans (Vicia fabaL.). J Agric Sci 81(3):445-448

Zietkiewicz EA, Rafalski LD (1994) Genome fingerprinting by simple sequence repeats (SSR)-anchored polymerase chain reaction amplification. Genomics 20(2):176-183

\section{Submit your manuscript to a SpringerOpen ${ }^{\circ}$ journal and benefit from:}

- Convenient online submission

- Rigorous peer review

- Open access: articles freely available online

High visibility within the field

- Retaining the copyright to your article

Submit your next manuscript at $\boldsymbol{\nabla}$ springeropen.com 